\title{
On the article: „Differences in socio-cognitive filters - Illustrating an understanding of the information overload problem in the course of transformation processes“
}

\author{
Füzyovà Luba*
}

To join the internationalization process is one of the main conditions for further development of Slovak enterprises. Transition of the companies to market economy means an accelerated transformation considering not only company property but also technologies, managerial skills, organizational changes in work organization. In the course of transformation it is very important to implement information and communication technologies creating opportunities for market coordination. Information has become a purposeful and practical knowledge needed for company target coordination, for the preparation of the decision-making process as well as for the creation of market relations. Information and communication technologies not only facilitate reaching the targets from qualitative and quantitative points of view but also creating new opportunities of company strategy.

The information system plays an important role in the international corporation which has to solve the interrelations between parent organization and its branches and subsidiaries in different countries. It is possible to specify various types of company approaches. One of them is a polycentric approach where a strong stress on different local and national conditions of the company environment leads to renouncing the single unilateral influence of the parent organization and where the particularities of subsidiaries are considered.

The author of the article decided to illustrate in his paper the above mentioned problems, i.e. transformation process, management practice and information overload problems in Swiss - based international corporation Holderbank and its branch HIROCEM in Slovakia.

It is possible to agree with the author's affirmation in the first part of the article that the information overload problem in our geographic conditions is the reason for "ambiguity". The illustrative example of Holderbank corporation refers to a high level of business management decentralization in branches and subsidiaries abroad and on the other hand points out the need to create a central information database for individual fraction areas. The opinions of HIROCEM

Füzyovà Luba, Faculty of Business Management, University of Economics Bratislava 
managers cited in the paper illustrate the differences in the approaches to information processing and use.

A certain autonomy of the corporation which follows from polycentric management gives opportunities for the HIROCEM management to gradually develop a socio-cognitive filter allowing to acquire the information needed in the decision-making process "and abolish the threat" of an information overload in the course of transformation changes.

Conclusion: The paper is an interesting illustration of links between an international corporation and its branches in a transforming economy and at the same time it is an excellent information on transformation problems in Slovakia. 